\title{
Reactor Physics Experiment in a Graphite-Moderation System for HTGR Y.Fukaya ${ }^{1}$
}

\author{
${ }^{1}$ Sector of Fast Reactor and Advanced Reactor Research and Development, Japan Atomic \\ Energy Agency, fukaya.yuji@jaea.go.jp
}

\author{
M. Goto ${ }^{1}$, S. Nakagawa ${ }^{1}$, K. Nakajima ${ }^{2}$, K. Takahashi² ${ }^{2}$ A. Sakon², T. Sano ${ }^{2}$, \\ and K. Hashimoto ${ }^{2}$, \\ 2 Graduate School of Science and Engineering, Kindai University, goto.minoru@jaea.go.jp, \\ nakagawa.shigeaki@jaea.go.jp,kunihironnakajima@nk-mail.com, \\ takahashi.kazuki0524@gmail.com,sakon@kindai.ac.jp,t-sano@kindai.ac.jp, \\ kengoh@pp.iij4u.or.jp
}

\begin{abstract}
The Japan Atomic Energy Agency (JAEA) started the Research and Development (R\&D) to improve nuclear prediction techniques for High Temperature Gas-cooled Reactors (HTGRs). The objectives are to introduce a generalized bias factor method to avoid full mock-up experiment for the first commercial HTGR and to introduce reactor noise analysis to High Temperature Engineering Test Reactor (HTTR) experiment to observe sub-criticality. To achieve the objectives, the reactor core of graphite-moderation system named B7/4"G2/8"p8EUNU+3/8"p38EU(1) was newly composed in the B-rack of Kyoto University Critical Assembly (KUCA). The core is composed of the fuel assembly, driver fuel assembly, graphite reflector, and polyethylene reflector. The fuel assembly is composed of enriched uranium plate, natural uranium plate and graphite plates to realize the average fuel enrichment of HTTR and it's spectrum. However, driver fuel assembly is necessary to achieve the criticality with the small-sized core. The core plays a role of the reference core of the bias factor method, and the reactor noise was measured to develop the noise analysis scheme. In this study, the overview of the criticality experiments is reported. The reactor configuration with graphite moderation system is rare case in the KUCA experiments, and this experiment is expected to contribute not only for an HTGR development but also for other types of a reactor in the graphite moderation system such as a molten salt reactor development.
\end{abstract}

KEYWORDS: Graphite-moderation system, HTGR, KUCA, B-rack, Reactor physics experiment

\section{INTRODUCTION}

After the Fukushima Daiichi nuclear accident [1] in 2011, High Temperature Gas-cooled Reactors (HTGRs) has attracted considerable attention from the viewpoint of outstanding safety [2]. In this situation, a design study of HTGR for commercial application was started [3] in the Japan Atomic Energy Agency (JAEA) in cooperation with Japanese vendors which have experience of construction of High Temperature Engineering Test Reactor (HTTR) [4]. The Research and Development (R\&D) to improve nuclear prediction techniques also started in connect with this.

The objectives are to introduce a generalized bias factor method [5] to avoid full mock-up experiment for the first commercial HTGR and to introduce reactor noise analysis to HTTR experiment to observe sub- 
criticality. For the first objective, at least, two experimental data, which has different core characteristics, are necessary to synthesize sensitivity coefficient as same as target reactor's one. For the second objective, To determine neutron source strength is necessary to improve nuclear predication for Loss Of Forced Cooling accident (LOFC) experiment [6], which is necessary for safety of commercial reactor design, although it started before the Fukushima Daiichi nuclear accident. To this end, inverse kinetics method is useful. However, the measured neutron source strength depends on subcriticality. The subcriticality can be determined by noise analysis method planned to be introduced independently from neutron source length. With the measured subcriticality and inverse kinetics method, neutron source length can be determined.

To achieve the objectives, the reactor core of graphite moderation system named B7/4"G2/8"p8EUNU+3/8"p38EU(1) was newly configured in the B-rack of Kyoto University Critical Assembly (KUCA). The core plays a role of the reference core of the bias factor method, and the reactor noise was measured to develop the noise analysis scheme [7]. In this study, we report the core configuration and the detail of the experiment.

\section{CORE CONFIGURATION}

\subsection{Core Concept and Overview of HTTR}

The core should realize the similar characteristics of HTGR. Here, HTTR [4] is assumed to be a representative one. Table I shows the major specifications of the HTTR. The HTTR is a graphite-moderated and helium gas-cooled block-type HTGR, situated at JAEA-Oarai Research and Development Center. It has $30 \mathrm{MW}$ thermal power and its outlet coolant temperature, which can be used for nuclear heat utilization, is $850{ }^{\circ} \mathrm{C}$ in rated power operation. Additionally, the HTTR can also be operated in high temperature test operation mode, with which its outlet coolant temperature is $950{ }^{\circ} \mathrm{C}$.

Coated Fuel Particles (CFPs) [4], which have a function of preventing release fission products (FPs) from fuels to coolant, are used in the HTTR. Their maximum use temperature in normal operation condition is limited up to about $1495^{\circ} \mathrm{C}$ to retain the function under considered abnormal condition. Power distribution in the core is optimized to make fuel temperature below the limit. Specifically, the power distribution is made uniform in the radial direction, and relatively higher at coolant inlet side in the axial direction. The optimized distribution [8] is achieved by changing uranium enrichment (3-10 wt.\%U). Consequently, the average enrichment is $5.9 \mathrm{wt} \%$.

In this experiment, the graphite-moderation core is composed in solid moderator system rack of KUCA so called "B-rack" to mimic the HTTR core. The enrichment is mimicked by the combination of Highly Enrichment Uranium (HEU) plate which is composed of the alloy of $93 \mathrm{wt} \% \mathrm{HEU}$ and aluminum, and Natural Uranium (NU) metal plate. The average enrichment is $5.41 \mathrm{wt} \%$.

The HEU plate and NU plate are assembled with moderator plate to realize the spectrum of HTGR. Graphite is also employed as the moderator for the core in B-rack. However, the volume fraction of fuel material in HTGR is very small because the CFPs distribute in the graphite structure. The $\mathrm{Vm} / \mathrm{Vf}$ ratio is 76.8 in HTTR. To realize the soft spectrum of HTGR, polyethylene moderator is necessary in addition to the graphite moderator because the size of the B-rack is small. Moreover, to achieve criticality with the large leakage core, driver fuel assembly composed of HEU plate and polyethylene plate are deployed around the core. 
Table I. Major specification of HTTR

\begin{tabular}{|c|c|}
\hline Items & Values \\
\hline Thermal Power & $30 \mathrm{MW}$ \\
\hline Inlet and outlet coolant temperature & $395 \circ \mathrm{C} / 850-950{ }^{\circ} \mathrm{C}$ \\
\hline Core structure & Graphite \\
\hline Equivalent diameter & $2.3 \mathrm{~m}$ \\
\hline Effective height & $2.9 \mathrm{~m}$ \\
\hline Fuel & $\mathrm{UO}_{2}$ \\
\hline Uranium enrichment & $3-10 \mathrm{wt} \%$ (average $5.9 \mathrm{wt} \%)$ \\
\hline Burnup Period & 660 days \\
\hline
\end{tabular}

\subsection{Configuration of B7/4"G2/8"p8EUNU+3/8"p38EU(1) Core}

The configuration of the fuel assemblies is shown in Fig.1, and the core configuration is shown in Fig.2. "F" is the fuel assembly composed of 8 unit cells, which include a 1/16" thickness HEU plate, a $1 \mathrm{~mm}$ thickness NU plate, three 1/2" thickness graphite plates, a 1/4" thickness graphite plate, and two $1 / 8$ " thickness polyethylene plates, with axial graphite reflectors. The fuel plates were designed to realize the aver-aged fuel enrichment of HTTR as described above. The polyethylene plate was used to mimic the HTTR spectrum. "D" stands for the driver fuel assemblies composed of 38 unit cells, which include a 1/16" thickness enriched uranium plate, and, three $1 / 8$ " thickness of polyethylene, with axial graphite reflector. "d" stands for the partial length driver fuel to adjust criticality.

The core is surrounded by the graphite reflector, and it is surrounded by polyethylene reflector. The neutron spectrum of each region is compared with HTTR's as shown in Fig. 3. Those are calculated by MVP [9], which is a neutron transport calculation code based on Monte Carlo method. The HTTR spectrum is calculated by pin cell model with the average enrichment. The spectrums of the experimental core are those in the center elevation position. The fuel cells are named "T-12", "T-13", "T-14" and "T-15" from the outside of the core. The fuel cell of "T-12" is driver fuel, and other's are ordinary fuel. The spectrum slightly becomes harder for inner direction. Due to the polyethylene moderator, the shapes are similar to that of light water reactor. However, the peak of Maxwell distribution, which is dominant to sensitivity for generalized bias factor method, is successfully realized. For noise analysis, the neutron path of graphite reflector is deployed to the left side of the core to observe the depletion of the correlation information in the neutron noise.

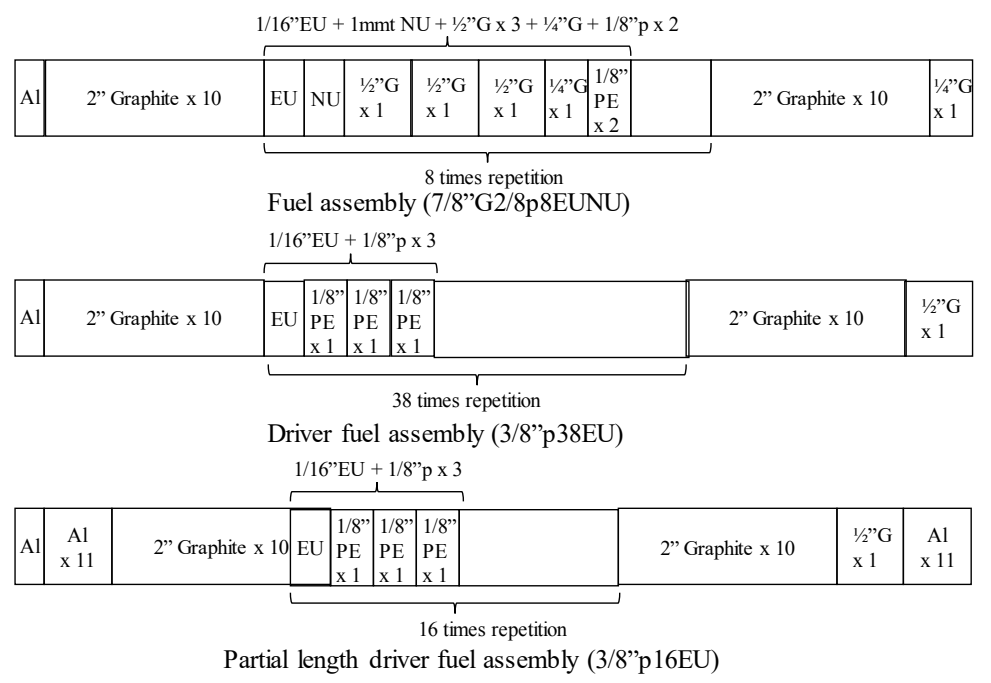

Figure 1. Configuration of fuel assemblies. 


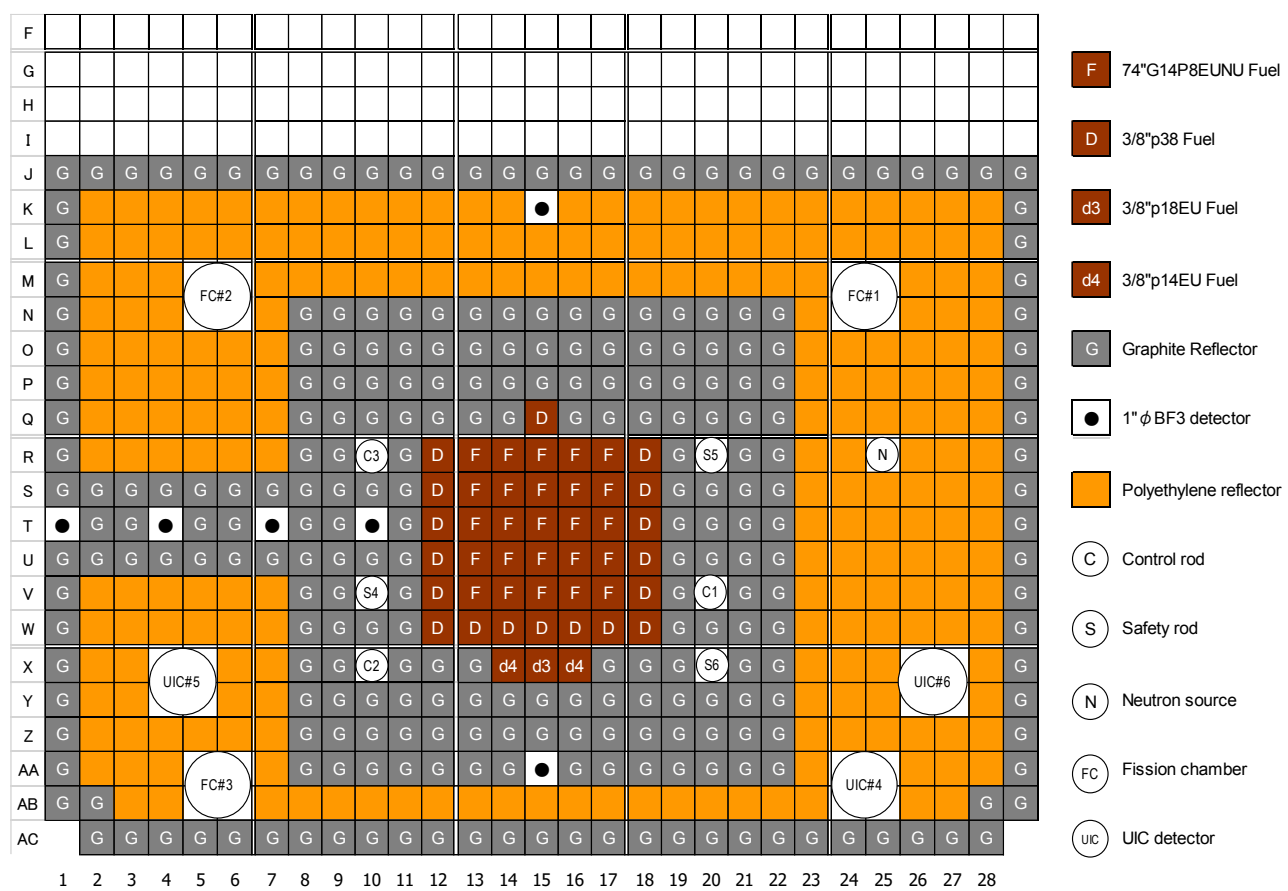

Figure 2. Configuration of core.

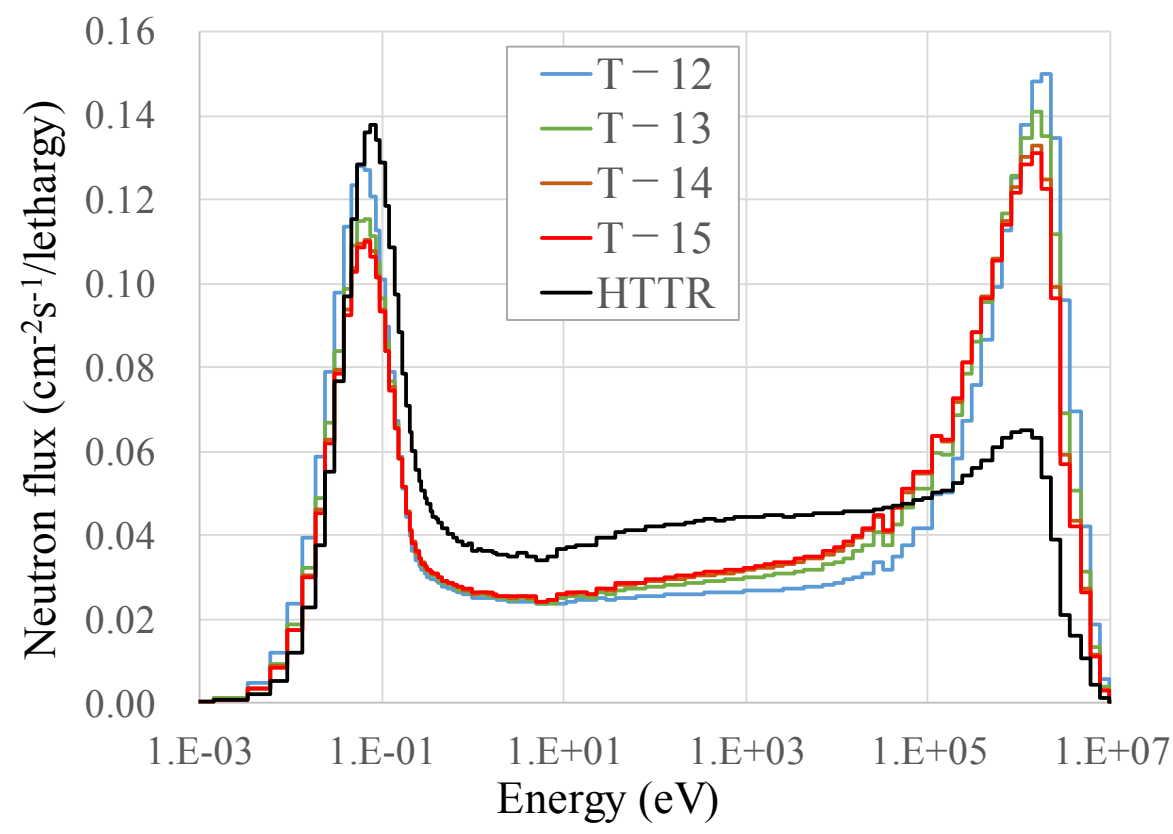

Figure 3. Comparison of neutron spectrum.

\subsection{Quality of Graphite}

The quality of the graphite block is dominant to determine criticality because the bulk density is significantly smaller than the theoretical density due to the vacancy between the crystal structures and impurities prevent the criticality. The bulk density of the graphite used in this experiment is $1.70 \mathrm{~g} / \mathrm{cm}^{3}$. The impurities correspond to approximately $1 \mathrm{ppm}$ of boron equivalent content, and it is classified as high purity nuclear graphite [10]. The poison effect is approximately $0.1 \% \Delta \mathrm{k} / \mathrm{k}$ in this system. 


\section{EXPERIMENT}

\subsection{Approach to Criticality}

Figure 4 shows the process in an approach to criticality. First, ordinary fuel and driver fuel assemblies are loaded from Step 0 to Step 4. Next, partial length driver fuel assemblies are loaded to adjust criticality from Step 5 to Step 7. Finally, the core reached to criticality with $930 \mathrm{HEU}$ plates and 7 steps of the approach to criticality.

Figure 5 shows the inverse count rate during the criticality approach. The detector positions are slightly different from the experimental core shown in Fig.2. The calculated curve is also shown in the figure. The calculation is performed by MVP code with evaluated nuclear data library of JENDL4.0 [11]. The calculation curve is obtained only by considering multiplied neutrons. However, in the actual core, directly achieved neutrons from the neutron source are also counted in the detectors. Therefore, the curves by the fission chamber from FC\#1 to FC\#3 are observed upper side of the calculated curve. The trend is significant for that of FC\#1 because it was deployed near the neutron source.
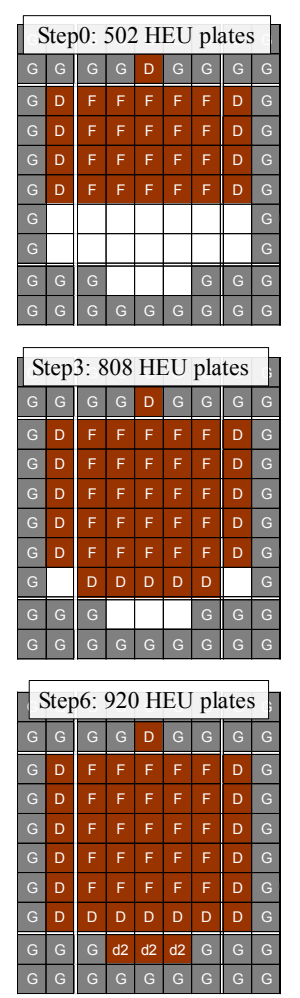
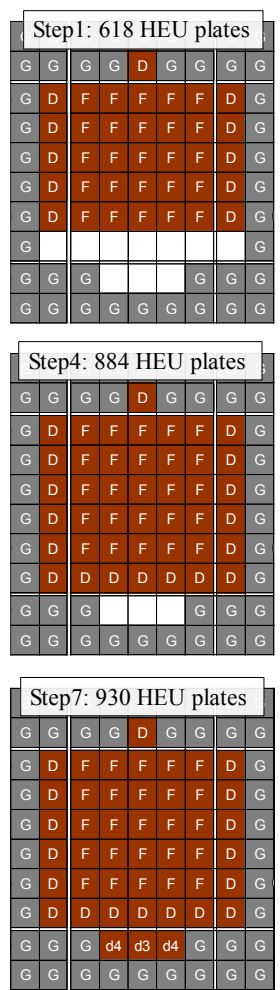
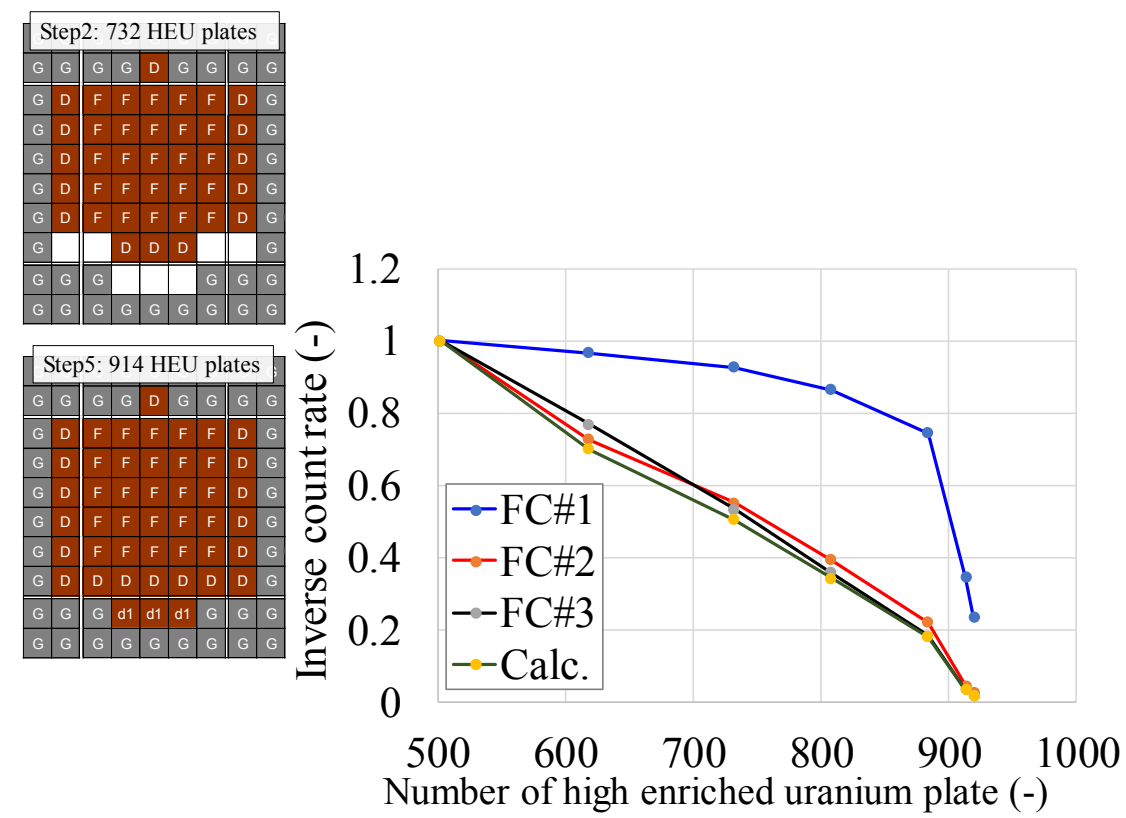

Figure 5. Inverse count rate in criticality approach.

Figure 4. Process of criticality approach.

\subsection{Reactivity Worth Measurement}

After that, reactivity worth of the core was measured. It is summarized in Table II with C/E values. The calculations were performed with JENDL4.0 [11], ENDF/B7.0 [12], and JEFF3.2 [13]. The experimental values were evaluated by period method for excess reactivity, by rod drop method with integral scheme for control rod, and by rod drop method with inverse kinetics analysis for center core [14]. For the excess 
reactivity measurement, it was performed by two steps because of its large reactivity worth. In the first step, control rod was inserted to measure a part of excess reactivity by compensation. The reactivity is negative. In the second step, target control rod was withdrawn completely. Here, the reactivity is positive. By summation of the two part of reactivity worth, The excess reactivity was measured.

By dropping the center core from the core system, the negative reactivity inserted by the loss of fuel material and delayed neutron precursor. For center core, the integral scheme is not suitable because the drop velocity is slow and against the assumption of the calculation theory. On the contrary, the inverse kinetics analysis can treat continuous reactivity insertion.

However, the $\mathrm{C} / \mathrm{E}$ values of the reactivity seem large. Therefore, measured multiplication factors and the $\mathrm{C} / \mathrm{E}$ values are compared as listed in TABLE III. and TABLE IV, V and VI, respectively for JENDL 4.0, $\mathrm{ENDF} / \mathrm{B} 7.0$ and JEFF 3.2. The calculated multiplication factor in the reference state of reactivity measurement can be regarded as $\mathrm{C} / \mathrm{E}$ from the Table IV to Table VI. because the state should be critical. It is found that the $\mathrm{C} / \mathrm{E}$ values of multiplication factors are almost unity. However, the slight difference is closed up in the evaluate of reactivity shown in TABLE III.

The calculated multiplication factors are small in the order of JENDL 4.0, JEFF 3.2 and ENDF/B 7.0. It depends on the difference of radiative capture cross sections of carbon. Those are 3.85, 3.81. 3.36 mbarn in the order. Historically, smaller cross-sections had employed for a long time. 3.53 mbarn employed for JENDL, and 3.36 mbarn for ENDF/B and JEFF. First, JENDL revised it to the larger cross section of 3.85 mbarn according to the validation with the excess reactivity calculation of HTTR [15]. Others followed to the revision of JENDL. Finally, ENDF/B also employed the larger cross section of 3.86 mbarn in the version of 7.1. In addition, JEFF 3.2 employed 3.81 mbarn in the revision. For ${ }^{12} \mathrm{C}$, the cross section of 3.86 mbarn was employed, and it is modified with considering the isotope abundance of ${ }^{13} \mathrm{C}$. According to this calculation, the result with JEFF 3.2 shows most reasonable result.

Table II. Measured reactivity worth and $\mathbf{C} / \mathbf{E}$ value: Errors correspond to $2 \sigma$

\begin{tabular}{|l|l|l|l|l|}
\hline & Reactivity & \multicolumn{3}{|c|}{ C/E } \\
\cline { 2 - 5 } & $(\% \Delta \mathrm{k} / \mathrm{k})$ & JENDL 4.0 & ENDF/B7.0 & JEFF3.2 \\
\hline Excess & $0.200 \pm 0.004$ & $1.34 \pm 0.18$ & $1.25 \pm 0.18$ & $1.52 \pm 0.18$ \\
\hline Control rod C1 & $0.880 \pm 0.060$ & $1.20 \pm 0.09$ & $1.22 \pm 0.09$ & $1.20 \pm 0.09$ \\
\hline Control rod C2 & $0.587 \pm 0.039$ & $1.11 \pm 0.09$ & $1.11 \pm 0.09$ & $1.14 \pm 0.09$ \\
\hline Control rod C3 & $0.535 \pm 0.035$ & $1.10 \pm 0.09$ & $1.07 \pm 0.09$ & $1.01 \pm 0.09$ \\
\hline Center core & $3.815 \pm 0.068$ & $1.02 \pm 0.02$ & $1.01 \pm 0.02$ & $1.02 \pm 0.02$ \\
\hline
\end{tabular}

Table III. Measured multiplication factor and reactivity: Errors correspond to $2 \sigma$

\begin{tabular}{|l|l|l|l|}
\hline & $\begin{array}{l}\text { Multiplication factor } \\
\text { (reference) }\end{array}$ & $\begin{array}{l}\text { Multiplication factor } \\
\text { (reactivity inserted) }\end{array}$ & Reactivity $(\% \Delta \mathrm{k} / \mathrm{k})$ \\
\hline Excess $(1 / 2)$ & $1.00000 \pm 0$ & $0.99898 \pm 0.00004$ & $0.102 \pm 0.004$ \\
\hline Excess $(2 / 2)$ & $0.99899 \pm 0$ & $1.00002 \pm 0.00001$ & $0.098 \pm 0.001$ \\
\hline Control rod C1 & $1.00000 \pm 0$ & $0.99559 \pm 0.00060$ & $0.880 \pm 0.060$ \\
\hline Control rod C2 & $1.00000 \pm 0$ & $0.99706 \pm 0.00039$ & $0.587 \pm 0.039$ \\
\hline Control rod C3 & $1.00000 \pm 0$ & $0.99732 \pm 0.00034$ & $0.535 \pm 0.035$ \\
\hline Center core & $1.00000 \pm 0$ & $0.97074 \pm 0.00065$ & $3.815 \pm 0.068$ \\
\hline
\end{tabular}


Table IV. C/E value of multiplication factor and reactivity with JENDL 4.0: Errors correspond to $2 \sigma$

\begin{tabular}{|l|l|l|l|}
\hline & $\begin{array}{l}\text { Multiplication factor } \\
\text { (reference) }\end{array}$ & $\begin{array}{l}\text { Multiplication factor } \\
\text { (reactivity inserted) }\end{array}$ & Reactivity \\
\hline Excess $(1 / 2)$ & $0.99753 \pm 0.00018$ & $0.99597 \pm 0.00018$ & $1.55 \pm 0.26$ \\
\hline Excess $(2 / 2)$ & $0.99597 \pm 0.00018$ & $0.99706 \pm 0.00018$ & $1.11 \pm 0.26$ \\
\hline Control rod C1 & $0.99737 \pm 0.00018$ & $0.98696 \pm 0.00018$ & $1.20 \pm 0.09$ \\
\hline Control rod C2 & $0.99735 \pm 0.00018$ & $0.99090 \pm 0.00018$ & $1.11 \pm 0.09$ \\
\hline Control rod C3 & $0.99706 \pm 0.00018$ & $0.99126 \pm 0.00018$ & $1.10 \pm 0.09$ \\
\hline Center core & $0.99745 \pm 0.00018$ & $0.96021 \pm 0.00018$ & $1.02 \pm 0.02$ \\
\hline
\end{tabular}

Table V. C/E value of multiplication factor and reactivity with ENDF/B7.0: Errors correspond to $2 \sigma$

\begin{tabular}{|l|l|l|l|}
\hline & $\begin{array}{l}\text { Multiplication factor } \\
\text { (reference) }\end{array}$ & $\begin{array}{l}\text { Multiplication factor } \\
\text { (reactivity inserted) }\end{array}$ & Reactivity \\
\hline Excess $(1 / 2)$ & $1.00031 \pm 0.00018$ & $0.99865 \pm 0.00018$ & $1.64 \pm 0.26$ \\
\hline Excess $(2 / 2)$ & $0.99865 \pm 0.00018$ & $1.00001 \pm 0.00018$ & $1.39 \pm 0.26$ \\
\hline Control rod C1 & $1.00038 \pm 0.00018$ & $0.98989 \pm 0.00018$ & $1.20 \pm 0.09$ \\
\hline Control rod C2 & $1.00038 \pm 0.00018$ & $0.99376 \pm 0.00018$ & $1.14 \pm 0.09$ \\
\hline Control rod C3 & $1.00001 \pm 0.00018$ & $0.99463 \pm 0.00020$ & $1.01 \pm 0.09$ \\
\hline Center core & $1.00040 \pm 0.00018$ & $0.96299 \pm 0.00018$ & $1.02 \pm 0.02$ \\
\hline
\end{tabular}

Table VI. C/E value of multiplication factor and reactivity with JEFF3.2: Errors correspond to $2 \sigma$

\begin{tabular}{|l|l|l|l|}
\hline & $\begin{array}{l}\text { Multiplication factor } \\
\text { (reference) }\end{array}$ & $\begin{array}{l}\text { Multiplication factor } \\
\text { (reactivity inserted) }\end{array}$ & Reactivity \\
\hline Excess $(1 / 2)$ & $0.99964 \pm 0.00018$ & $0.99827 \pm 0.00018$ & $1.36 \pm 0.26$ \\
\hline Excess $(2 / 2)$ & $0.99827 \pm 0.00018$ & $0.99938 \pm 0.00018$ & $1.14 \pm 0.26$ \\
\hline Control rod C1 & $0.99980 \pm 0.00018$ & $0.98919 \pm 0.00018$ & $1.22 \pm 0.09$ \\
\hline Control rod C2 & $0.99975 \pm 0.00018$ & $0.99329 \pm 0.00018$ & $1.11 \pm 0.09$ \\
\hline Control rod C3 & $0.99938 \pm 0.00018$ & $0.99368 \pm 0.00018$ & $1.07 \pm 0.09$ \\
\hline Center core & $0.99972 \pm 0.00018$ & $0.96277 \pm 0.00018$ & $1.01 \pm 0.02$ \\
\hline
\end{tabular}

\section{SUMMARY}

To improve nuclear prediction techniques for HTGR, the graphite moderation core named B7/4"G2/8"p8EUNU+3/8"p38EU(1) was newly configured in the B-rack of KUCA. In this study, the detail of the experiment is reported. Major results are as follows.

$>$ The core is configured to mimic HTTR spectrum.

$>$ Because of the large value of $\mathrm{Vm} / \mathrm{Vf}$ ratio of HTGR, polyethylene moderator should be deployed in additional to the graphite moderator.

To achieve criticality with the small seized B-rack of KUCA, driver fuel, which is moderated only polyethylene moderator, should be deployed.

$>$ Although the spectrum is similar to the light water reactor, the Maxwell peak of HTTR spectrum was successfully realized. It is expected that the core sensitivity is similar to HTTR's.

$>$ To develop noise analysis method for HTGR, the neutron leak path with graphite block was deployed to evaluate depletion of correlation information in the noise. The part of the study will be also reported [7]. 
Moreover, the detail of the approach of criticality and reactivity worth are also reported and discussed.

In this experiment, reference core of generalized bias factor method is configured. In the future, we are planning to configure secondary core and apply the method to HTGR design.

In addition, the result of this criticality experiment is expected to contribute to not only the HTGR development but also other types of reactors of the graphite moderation such as the molten salt reactor.

\section{ACKNOWLEDGMENTS}

We appreciate Dr. E. Ishitsuka, Mr. T. Uesaka, Mr. S. Kawakami, and Mr. K. Morita of JAEA and operator of KUCA who support the core configuration and operation.

\section{REFERENCES}

1. AESJ, The Fukushima Daiichi Nuclear Accident: Final Report of the AESJ Investigation Committee, pp. 560, Springer, (2015).

2. H. Ohashi, H. Sato, Y. Tachibana, et al., "Concept of an inherently-safe high temperature gas-cooled reactor," Proc of ICANSE 2011, Bali, Indonesia, November 14-17, pp. 50-58 (2011).

3. Y. Fukaya, N. Mizuta, M. Goto, et al., "Conceptual design study of a high performance commercial HTGR," Proc of HTR 2018, Warsaw, Poland, October 8-10, \#101 (2018).

4. S. Saito, T. Tanaka, Y. Sudo et al., Design of High Temperature Engineering Test Reactor (HTTR), Japan Atomic Energy Research Institute, JAERI-1332 (1994).

5. T. Sano, T. Takeda, "Generalized Bias Factor Method for Accurate Prediction of Neutronics Characteristics," J. Nucl. Sci. Techonol., 43(12), pp.1465-1470 (2006).

6. OECD/NEA, NEA Loss of Forced Coolant (LOFC) Project,

URL: https://www.oecd-nea.org/jointproj/lofc.html

7. A. Sakon, K, Nakajima, K. Takahashi, et al., "Reactor noise analysis for a graphite-moderated and reflected core in KUCA," Proc of PHYSOR 2020, Cambridge, U.K., March 29 - April 2, (2020).

[to be published]

8. K. Yamashita, S. Maruyama, I. Murata, et al., "Optimization of Power Distribution to Achieve Outlet Gas-Goolant Temperature of 950 ○C for HTTR,” J. Nucl. Sci. Techonol., 29(5), pp.472-481 (1992).

9. Y. Nagaya, K. Okumura, T. Mori, “A Monte Carlo neutron/photon transport code MVP 2," Trans. Am. Nucl. Soc., 95(1), pp.662-663 (2006).

10. ASTM, "ASTM D7301-11(2015): Standard Specification for Nuclear Graphite Suitable for Components Subjected to Low Neutron Irradiation Dose, " ASTM International, West Conshohocken, PA, (2015).

11. K. Shibata, O. Iwamoto, T. Nakagawa, et al., "JENDL-4.0; A New library for nuclear science and engineering," J. Nucl. Sci. Techonol., 48(1), pp.1-30 (2011).

12. M. B. Chadwick, P. Oblozinsky, M. Herman, et al., "ENDF/B-VII.0: Next Generation Evaluated Nuclear Data Library for Nuclear Science and Technology," Nuclear Data Sheets, 107, pp.2931-3060 (2006).

13. OECD/NEA Data Bank, JEFF-3.2 Evaluated Data Library-Neutron data, OECD/NEA (2014). URL: http://www. oecd-nea.org/dbforms/data/eva/evatapes/jeff_32/

13. K. Takahashi, K. Nakajima, A. Sakon, et al., "R\&D to improve accuracy of nuclear prediction for HTGR, (2) Inverse Kinetics Analysis for HTTR Simulated Core in KUCA," fall meeting of AESJ, Toyama, Japan, Sept. 11-13, 2J15,(2019).

14. M. Goto, S. Shimakawa, Y. Nakao, et al., "Impact of revised thermal neutron capture cross section of carbon stored in JENDL-4.0 on HTTR criticality calculation," J. Nucl. Sci. Techonol., 48(7), pp.965969 (2011). 